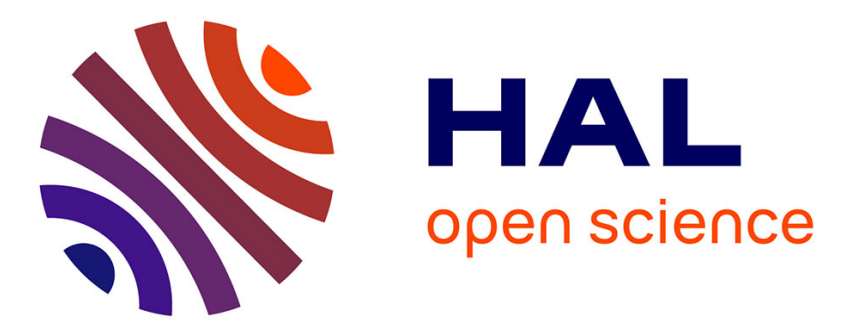

\title{
Insight of patients and their parents into schizophrenia: Exploring agreement and the influence of parental factors
}

Alexandra Macgregor, Joanna Norton, Catherine Bortolon, Melissa Robichon, Camille Rolland, Jean-Philippe Boulenger, Stéphane Raffard, Delphine

Capdevielle

\section{To cite this version:}

Alexandra Macgregor, Joanna Norton, Catherine Bortolon, Melissa Robichon, Camille Rolland, et al.. Insight of patients and their parents into schizophrenia: Exploring agreement and the influence of parental factors. Psychiatry Research, 2015, 228 (3), pp.879-886. 10.1016/j.psychres.2015.05.005 . hal-01987727

\section{HAL Id: hal-01987727 https://hal.science/hal-01987727}

Submitted on 21 Jan 2019

HAL is a multi-disciplinary open access archive for the deposit and dissemination of scientific research documents, whether they are published or not. The documents may come from teaching and research institutions in France or abroad, or from public or private research centers.
L'archive ouverte pluridisciplinaire HAL, est destinée au dépôt et à la diffusion de documents scientifiques de niveau recherche, publiés ou non, émanant des établissements d'enseignement et de recherche français ou étrangers, des laboratoires publics ou privés. 


\title{
Insight of patients and their parents into schizophrenia: Exploring agreement and the influence of parental factors
}

\author{
Alexandra Macgregor a,d, n, Joanna Norton b,d, Catherine Bortolon a,c, Melissa Robichon a , \\ Camille Rolland a , Jean-Philippe Boulenger ${ }^{\text {a,d }}$, Stéphane Raffard $\quad{ }^{a, c}$, Delphine Capdevielle a,b,d \\ a University Department of Adult Psychiatry, Hôpital la Colombière, Montpellier University Hospital, Montpellier, France \\ ${ }^{\mathrm{b}}$ INSERM, U-1061, Hôpital la Colombiere, Montpellier, France \\ ${ }^{c}$ Epsylon Laboratory Dynamic of Human Abilities \& Health Behaviors, Université Paul Valéry, Montpellier, France \\ d Université Montpellier, Montpellier, France

Poor insight is found in up to $80 \%$ of factors of which cognitive functioning, associations between patient insight and that of their biological parents', factors. Insight was assessed in 41 patients and their biological assessment of Unawareness of Mental critical attitudes were assessed with validated self-report cognitive assessments for working memory and executive functioning parents was not associated for any of the SUMD dimensions but a significant correlation was found
between patient and parent awareness of treatment effect for patient-parent dyads with frequent daily contact. Low parental critical attitude was associated with higher patient awareness of symptoms and a high parental memory task score with high patient insight. Our study is the first to suggest a possible influence of parental factors such as critical attitudes and cognitive performance on patient insight.
Keywords: Schizophrenia Insight Cognition Family Psycho-education

\section{Introduction}

Lack of insight affects up to $80 \%$ of patients suffering from schizophrenia (Amador et al., 1994) and has become a topic of increasing interest over the past 20 years. Originally considered as a single entity, either present or absent in patients, clinical insight is today recognised as a multidimensional construct comprising awareness of having a mental disorder, of treatment effects, of social consequences of mental disorder and of specific symptoms, as well as the ability to attribute symptoms to the disorder. negative impact of poor insight on treatment adherence (Amador et al., 1993), functional outcome (Lincoln et al., 2007) and disease prognosis (Schwartz et al., 1997) has encouraged researchers to explore the various factors underlying insight in schizophrenia, thus inspiring clinicians to offer diverse interventions aiming to improve patients' awareness of disease (Pijnenborg et al., 2013).

Despite the strong evidence, (Shad et al., 2006; Raffard et al., 2009; Boyer et al., 2012; Liemburg et al., 2012; Raij et al., 2012; van der Meer et al., 2013) prefrontal cortex dysfunction alone cannot

\footnotetext{
${ }^{n}$ Correspondence to: University Department of Adult Psychiatry, Hôpital la Colombière, 39 Avenue Charles Flahault 34295 Montpellier Cedex 5, France. Tel.: p33 4673397 02; fax: p33 467339660 .

E-mail address: a-macgregor@chu-montpellier.fr (A. Macgregor).
}

explain the complexity of poor insight in psychosis. Other psychological (Lysaker et al., 2003a; 2003b), social and environmental factors (Johnson and Orrell, 1995; White et al., $\quad 2000$; Pruß et al., 2012), have also been associated to it but very little research has focused specifically on familial factors.

To date, only a few studies have compared caregivers' and patients' insight into illness (Smith et al., 1997; Gigante and Castel, 2004; Tranulis et al., 2008; Brent et al., 2011). However, findings are inconsistent due to the different scales used to measure insight and study populations. Two studies assessed insight with the SUMD (Scale to Assess Unawareness of Mental Disorder) (Smith et al., 1997; Brent et al., 2011), one used a non validated Portuguese translation of David's Scale for the Assessment of Insight (SAI) (Gigante and Castel, 2004), and one created an "Extracted Insight Score" (Tranulis et al., 2008). Caregiver insight of patients' mental disorder was assessed with modified versions of the same scales. Smith et al. (1997) compared insight scores between groups of patients and their significant others, finding no significant difference between the scores in the two groups for all SUMD dimensions except for attribution of symptoms. Correlation coefficients were not calculated. The other three studies found significant correlations between patient and caregivers' insight but not for all dimensions (Gigante and Castel, 2004; Brent et al., 2011) and coefficients were often moderate to low (Gigante and Castel, 2004; 
Tranulis et al., 2008). Furthermore sample sizes were modest (14 (Brent et al., 2011), 18 (Tranulis et al., 2008) 22 (Smith et al., 1997) and 40 (Gigante and Castel, 2004) patient-caregiver dyads), patient diagnoses were heterogeneous (comprising all schizophrenia spectrum disorders including first episode psychosis) and caregiver groups did not focus specifically on biological relatives.

To our knowledge, none of these studies directly explored associations between family or caregiver factors and patient insight. Brent's study does however provide indirect support for the hypothesis of an association between patient insight and caregiver levels of criticism assessed by the Patient Rejection Scale (PRS) as far as it found a correlation between lower caregiver PRS scores and better caregiver insight, and that in the same study certain dimensions of caregiver and patient insight were related. Another study explored the impact of family history of schizophrenia on patient insight (Danki et al., 2007), but no further literature is available on the other parental factors that may influence patients' insight. Yet the impact of patient's entourage on treatment adherence and clinical course is well established whether it be via expressed emotion levels or family interventions (Sellwood et al., 2003). Cognitive dysfunction found in healthy first degree relatives of schizophrenia patients (Snitz et al., 2006) could also explain altered parental insight into their offspring's disorder. Furthermore, parental knowledge about schizophrenia could also impact patients' own awareness of illness as it has been associated to stigma which itself is associated to insight and social distance (Pruß et al., 2012).

The main objective of this paper was to study the association between insight in schizophrenia patients and that of their biological parents, overall and according to daily contact. Our hypothesis was that high parental insight would be associated with high patient insight and that daily contact would increase association strength. We then sought to explore what other parental factors could be associated with patient insight, our hypothesis being that better cognitive functioning, lower expressed emotion levels, and better knowledge about schizophrenia in parents would be associated with higher patient insight levels.

\section{Methods}

\subsection{Subjects and inclusion procedure}

Between January 2012 and March 2014, we recruited patients meeting DSM IV criteria for schizophrenia (American Psychiatric Association, 1994), currently receiving inpatient or outpatient care in the Montpellier University Psychiatric Hospital (the Montpellier Insight Study). None were in the acute phase of psychosis (for inpatients, minimum of three weeks between admission and participation in the study). Inclusion criteria were being between 18 and 55 years of age and having a diagnosis of schizophrenia. Exclusion criteria were substance dependency other than cannabis or tobacco, substance abuse other than cannabis or alcohol, co-morbid neurological disorder, history of severe brain trauma or current electro-convulsive therapy. Parent inclusion criteria were being aged 75 years old or younger and able to come to the hospital to participate in the study. Parent exclusion criteria were co-morbid neurological disorder or history of severe brain trauma.

The flow chart in Fig. 1 describes the inclusion process. Patient participation rate was $43.6 \%$. In all, 41 patients participated for whom at least one parent did too. For 30 patients, only one parent participated, most often the mother $(23(76.7 \%))$; it was thus decided to use the mother's data when possible. For 7 patients only the father's data was available. All participants provided written consent after the nature of the procedures had been fully explained to them. The study design received approval by the French medical ethics committee.

Patients were assessed by a trained psychologist (C.R or M.R), parents were assessed by a psychiatrist $\quad$ (A.M.). Information was collected relating to sociodemographic status, substance-use disorders (DSM IV), current treatment and frequency of daily contact between patient and parent.

\subsection{Assessments}

\subsubsection{Clinical assessments}

Patients' symptom severity was assessed using the French version of the PANSS (Positive and Negative Symptom Scale) (Lançon et al., 1999). Parents' current and past psychiatric history was explored using the SCID-I semi-structured interview, validated in French (First et al., 2000). Parents' knowledge about schizophrenia was assessed using the Knowledge About Schizophrenia Test (KAST) which covers the origins of schizophrenia, it's manifestations and treatment in 18 multiple choice questions (Compton et al., 2007). Parents' critical attitudes were assessed by the Patient Rejection Scale (PRS), a self-report questionnaire of 24 items describing common rejecting attitudes towards patients with mental disorders (Kreisman et al., 1979; 1988). Items are scored on a Likert scale of 0 "never" to 7 "always".

\subsubsection{Insight assessment}

Current insight among patients was assessed with the French version of the SUMD (Raffard et al., 2010). Among parents we used a modified version in order to explore their insight into their offspring's disorder. The SUMD contains three general items assessing awareness of mental disorder (Q1), the effects of treatment (Q2) and the social consequences of the disorder (Q3), followed by 17 items assessing awareness and attribution of specific symptoms. Each item is scored on a Likert scale of 1 (full awareness/correct attribution) to 5 (totally unaware/erroneous attribution). Symptom awareness is only explored if the patient is sufficiently symptomatic (scoreZ3 on the PANSS scale for the corresponding symptom) and attribution is only assessed if the patient has sufficient awareness of the symptom ( $r 3$ on the SUMD). All patients had sufficiently high scores on the PANSS in order to explore awareness of at least three symptoms. For each subject we calculated an average symptom consciousness score, and an average symptom attribution score. A cut-off score was used to separate subjects with low insight (Z3) from those with high insight (Amador et al., 1993).

\subsubsection{Cognitive assessment}

Patients and their parents both underwent identical cognitive assessments. For subjects were read a series of 6-12 consonants and asked to immediately recollect and transcribe the last 6. The series were read in two blocks of 16 series. The dependent variable was calculated by averaging the number of consonants correctly (serially) remembered over all span levels. For executive functions we used the Wisconsin Card Sorting Test (WCST) for mental flexibility (Nelson, 1976) and the Behavioural Assessment for Dysexecutive Syndrome (BADS) for problem solving (Wilson et al., 1996). For the WCST we retained three variables most often associated with insight in the literature (Shad et al., 2006): the number of completed categories, number and percentage of perseverative errors. We used a shortened version of the BADS (Behavioural Assessment of Dysexecutive Syndrome) comprising five of the six subtests: action planning, the key search test, the temporal judgement test, the zoo test and the six elements test (Wilson et al., 1996). BADS total scores were converted to BADS IQ equivalents thus taking subject age into account.

\subsection{Statistical analysis}

The sample is described using percentages for categorical median and range for continuous variables with skewed distributions. was tested using the Shapiro-Wilk test. As distribution of insight was skewed, non parametric tests were used. Wilcoxon Test was used for comparing distributions between categories and the $\quad \chi^{2}$ Test or Fischer Test for testing associations between categorical variables. Correlation coefficients were calculated using Spearman's Test. This was considered preferable to using intra-class correlation as our distributions of insight are skewed. It is also the recommended dyadic analytical approach to measuring non-independence when dyads are distinguishable (Kenny et al., 2006). Comparison of patient and parent insight as categorical variables (high versus low) was performed with the McNemar paired $\quad \chi^{2}$ Test, in the whole sample and in two separate groups according to the presence or absence of patient and parent daily contact. Statistical analyses were performed with SAS version 9.2 (SAS Institute. Inc. Cary. North-Carolina).

\section{Results}

\subsection{Sample characteristics}

The sample is described in table $1 . \quad$ Patients were mainly male $(82.9 \%)$ with a median duration of illness of 10 years [1-34]. None of the parents had a personal history of psychotic disorder. The median number of days of contact per month declared by the parents was 15 , ranging from 1 to 31 . Four patients $(9.7 \%)$ saw their caregiver less than 5 days a month and 6 patients $(14.6 \%)$ between 5 and 10 days a month. We defined frequent daily contacts as more than 27 days per month, this concerned $46.3 \%$ of dyads. 


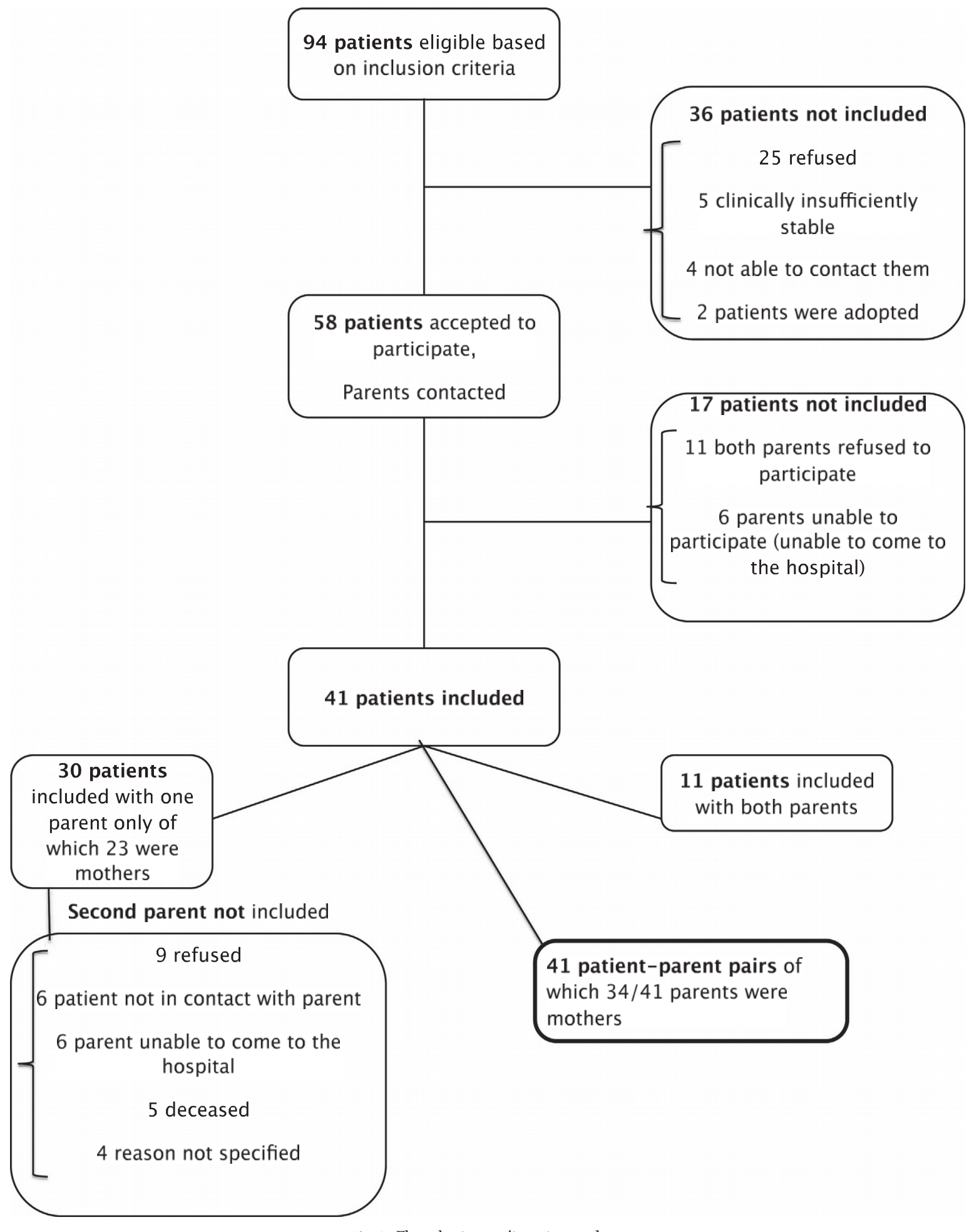

Fig. 1. Flow chart recruitment procedure.

\subsection{Insight into illness in patients and parents}

Parents had signi ficantly higher insight levels than their offspring in all dimensions explored by the SUMD (Fig. 2a). Correlation coef ficients between patients' and parents' insight scores were small ( o 0.29) for all five dimensions and not signi ficant.

After stratifying the sample according to daily contacts, insight was no longer signi ficantly higher in parents compared to patients, among those who had frequent daily contacts except for awareness of illness ( $\left.\begin{array}{llll}N & 19\end{array}\right)$ (Fig. 2b). Correlations between patient and parent insight scores in this group reached signi ficance for the awareness of treatment dimension (6t/4 0.48 $\mathrm{p} 1 / 4$ 0.04).Other correlation coefficients were all 00.41 and $p$ values 40.08$)$. Among patients and parents without frequent daily contact $\left(N_{1 / 22}\right)$ differences in high insight between the groups remained signi ficant except for awareness of symptoms (Fig. 2c) and correlation coefficients were not significant (all correlation coefficients ro $0.18, p$-values 40.42 ). 


\begin{tabular}{|c|c|c|c|c|}
\hline & \multicolumn{2}{|c|}{ Patients N1/441 } & \multicolumn{2}{|c|}{ Parents N1/441 } \\
\hline & $\mathrm{n}$ & $\%$ & $\mathrm{n}$ & $\%$ \\
\hline Sex (male) & 34 & 82.9 & 7 & 17.1 \\
\hline Age (years) (median [min-max]) & 39 & 29 [20-53] & 39 & $58[43-75]$ \\
\hline Education (years) (median [min-max]) & 39 & $11[8-17]$ & 39 & $12[5-18]$ \\
\hline Family situation (single) & 41 & 100 & 18 & 43.9 \\
\hline Living alone & 19 & 46.3 & 7 & 17.1 \\
\hline Duration of illness(years) (median [min-max]) & 41 & $10[1-34]$ & & \\
\hline \multicolumn{5}{|l|}{ Psychotropic treatment: } \\
\hline Chlorpromazine eq (mg) (median [min-max]) & 40 & $600[60-3500]$ & 0 & 0 \\
\hline Diazepam eq (mg) (median [min-max]) & 18 & $20[5-120]$ & 0 & 0 \\
\hline Corrector & 8 & 19.5 & 0 & 0 \\
\hline Antidepressant & 8 & 19.5 & 10 & 24.4 \\
\hline \multicolumn{5}{|l|}{ PANSS (median [min-max]) } \\
\hline Positive symptom subscale & 41 & $14[7-31]$ & & \\
\hline Negative symptom subscale & 41 & $17[7-33]$ & & \\
\hline General psychopathology subscale & 41 & $35[23-55]$ & & \\
\hline Total score & 41 & 67 [43-99] & & \\
\hline Cannabis abuse/dependency & 8 & 19.5 & & \\
\hline Alcohol abuse & 2 & 4.9 & & \\
\hline Specific psycho-educational intervention & 16 & 39 & & \\
\hline \multicolumn{5}{|l|}{ Cognitive assessment: } \\
\hline Updating score (median [min-max]) & & & 38 & $22[12-33.5]$ \\
\hline \multicolumn{5}{|l|}{ WCST (median [min-max]) } \\
\hline $\mathrm{Nb}$ of categories completed & & & 39 & $6[3-6]$ \\
\hline $\mathrm{Nb}$ of perseverative errors & & & 39 & $10[3-37]$ \\
\hline$\%$ of perseverative errors & & & 39 & $10.4[4.3-28.9]$ \\
\hline BADS score (median [min-max]) & & & 39 & $98[58-123]$ \\
\hline \multicolumn{5}{|l|}{ Parent factors: } \\
\hline Frequent (4 27 days/month) contact with offspring & & & 19 & 46.3 \\
\hline KAST score (median [min-max]) & & & 41 & $16[8-18]$ \\
\hline PRS total score (median [min-max]) & & & 40 & $58[36-121]$ \\
\hline Parent personal history of axis I disorder : & & & 19 & 46.3 \\
\hline Psychotic disorder & & & 0 & 0 \\
\hline Mood disorder & & & 17 & 41.5 \\
\hline Anxious disorder & & & 6 & 14.6 \\
\hline
\end{tabular}

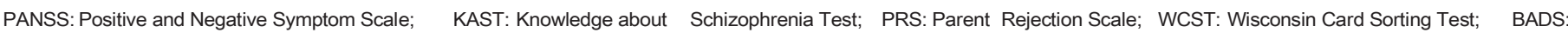
Behavioural Assessment of Dysexecutive Syndrome (IQ equivalent).

\subsection{Parental factors associated with patient insight}

Frequent daily contact as reported by the parents was significantly and positively associated to high patient awareness of the social consequences of illness (Table 2). The patient rejection score was associated with symptom awareness, with less parental criticism in the high patient insight group (median 47 [minmax: 36-88]) compared to the low insight group (median 67 [min-max: 46-121]) (po0.01) (Table 2).

Regarding the cognitive tests, the parents of patients with high insight (all 5 dimensions except for awareness of treatment response and symptom awareness) had a significantly higher median updating score reflecting better working memory. The parents of patients with high awareness of the social consequences of illness had a significantly higher median BADS score.

Parents' KAST scores were not significantly different between patients with high and low insight throughout all SUMD dimensions.

\section{Discussion}

Our study is the first to explore the association between patient and parent insight in a sample of patients with a diagnosis of schizophrenia and their biological parents. It is also the first to study parental factors influencing patient insight. Our findings do not support the hypothesis of an association between patient and parent insight based solely on the biological relationship between the two groups. However they suggest patients' awareness of treatment response may be influenced by the awareness of those they are in daily contact with, highlighting the need to encourage caregivers to reiterate the importance of treatment observance. Our study also suggests other parental factors such as daily contact, less rejecting attitudes and better cognitive performance are associated with high patient insight in certain dimensions. Thus, these factors could be targeted by specific programmes, aimed at caregivers, in the hope to improve patients' awareness of their illness. This is of important clinical relevance as it encourages the need to generalise and innovate family interventions which have already proven their efficacy on reducing expressed emotion (EE) levels (McWilliams et al., 2010) for example.

Our study is the first to explore the relationship between patient insight and parent rejection scores, extending the early findings of Brent et al. on caregiver insight and expressed emotion. Indeed, the association we found between better patient awareness of symptoms and less parental critical attitudes supports the hypothesis that patients' awareness of illness is partially influenced by the emotional attitudes and the behaviour of their families. Early literature on EE demonstrates that family members 


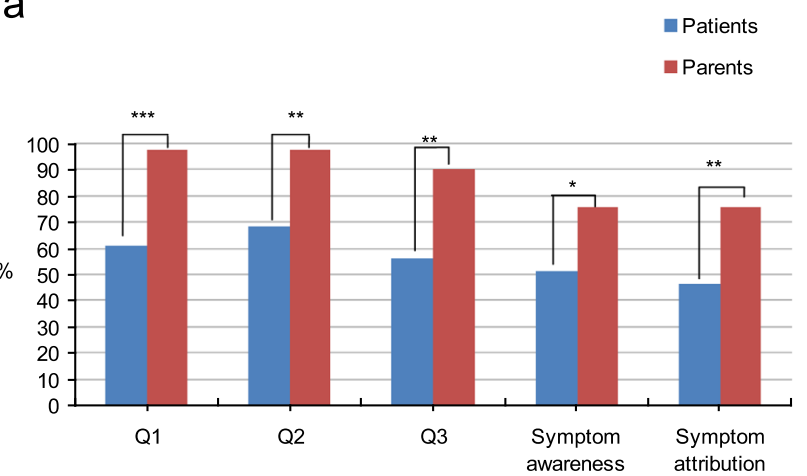

${ }^{*} p<0.02$
${ }^{* *} p<0.001$
${ }^{* *} p<0.0001$

Q1 Awareness of illness, Q2 Awareness of treatment effects, Q3 Awareness of consequences b

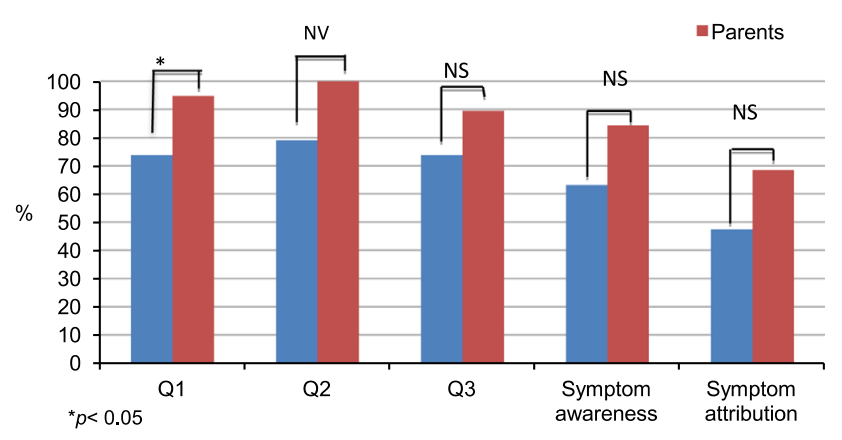

NS Not Significant

NV Chi ${ }^{2}$ Test not valid

Q1 Awareness of illness, Q2 Awareness of treatment effects, Q3 Awareness of consequences

C

-Patients

-Parents

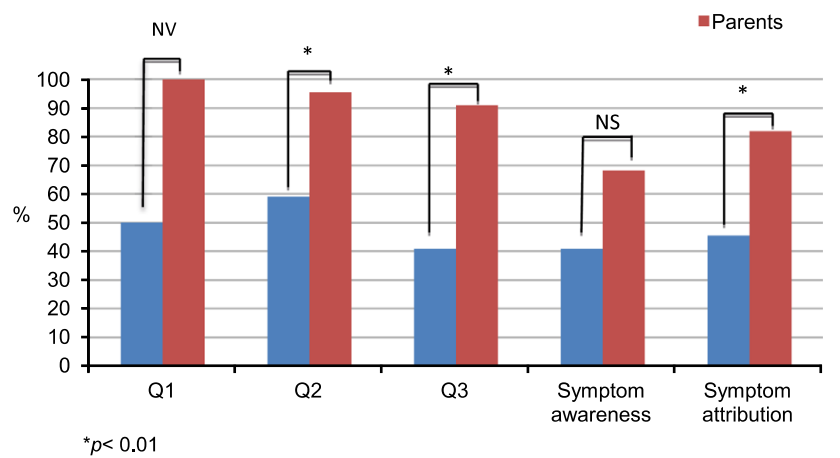

NS Not significant

NV Chi ${ }^{2}$ Test not valid

Q1 Awareness of illness, Q2 Awareness of treatment effects

Q3 Awareness of consequences

Fig. 2. (a) High insight rates in patients and parents (N 1/4 41). (b) High insight rates in patients and parents with frequent contacts ( $\mathrm{N} 1 / 419)$. (c) High insight rates in patients and parents with infrequent contacts $(\mathrm{N} 1 / 422)$.

with high EE levels are more often unaware of their ill relative's disorder (Vaughn and Leff, 1981). One can easily hypothesise that the same high EE levels can lead to patients feeling more shame and therefore being less open to self understanding about their illness. This hypothesis is further supported by work in developmental psychology on the relationship between parents' emotional characteristics, the quality of the child-parent bond and children's development of self and other understanding (Goodvin et al., 2008). Although less likely however, patient awareness of illness could also affect and improve parental attitudes.

In our study, parental knowledge about schizophrenia assessed by the KAST was not associated with patient insight. This could partially be due to lack of variability in KAST scores but also to high levels of knowledge, secondary to participation bias in parents in our study. Furthermore, the absence of association between parental knowledge and patient insight is in accordance with the literature on deficits in self-reflection in patients with schizophrenia, which renders their use of information about the disease, in this case obtained from parental knowledge, insufficient for achieving high insight (Wiffen et al., 2013). It also further supports the literature suggesting that knowledge on the biological and genetic origins of mental disorders do not reduce social distance or stereotype (Angermeyer et al., 2011). Thus knowledge about schizophrenia may not always be sufficient for parents to adopt understanding attitudes towards their offspring's symptoms and thereby helping to improve insight; and family interventions must have more ambitious objectives than simply providing information on disease.

Such programmes may also benefit from addressing the acceptance and mourning loss of function in order to reduce denial of symptoms as a path to further improve insight about illness. Then, longitudinal studies are necessary to study the impact of such interventions on patient insight via change in parental attitude for example.

On the other hand, our findings suggest that parents' cognitive performance in the form of a memory task is associated with their offspring's insight. Seeing as in schizophrenia patients, insight is associated with cognitive performance (Aleman et al., 2006), these leads us to question the existence of an association between parents' cognitive performance and their insight into their offspring's illness. Another publication issued from the Montpellier Insight Study supports this hypothesis (Raffard et al., 2014): in parents, higher awareness of their offspring's symptoms was associated with lower overconfidence in one's beliefs and higher Beck Cognitive Insight Scale (BCIS) total scores, which in turn were associated with better cognitive performance (executive functioning and verbal comprehension). The hypothesis of an association between parents' insight and their cognitive functioning is further supported by network dysfunctions in brain regions involved in self and other processing, found in non psychotic relatives schizophrenia patients when compared to healthy controls without a family history of mental disorders (Whitfield-Gabrieli et al., 2009; Brent et al., 2014). Thus there may be a biological basis as to insight alterations in first degree relatives of schizophrenia 
Parental factors associated with patient insight (scoreo3 versus 43) (median [min-max]).

\begin{tabular}{|c|c|c|c|c|c|c|c|c|c|c|}
\hline & \multicolumn{2}{|c|}{$\begin{array}{l}\text { Q1 : awareness of mental } \\
\text { disorder }\end{array}$} & \multicolumn{2}{|c|}{$\begin{array}{l}\text { Q2 : awareness of } \\
\text { treatment response }\end{array}$} & \multicolumn{2}{|c|}{$\begin{array}{l}\text { Q3 : awareness of social } \\
\text { consequences }\end{array}$} & \multicolumn{2}{|c|}{$\begin{array}{l}\text { Symptom awareness } \\
\text { score o3 }\end{array}$} & \multicolumn{2}{|c|}{$\begin{array}{l}\text { Symptom attribution score } \\
\text { o3 }\end{array}$} \\
\hline & No (16) & Yes (25) & No (13) & Yes (28) & No (18) & Yes (23) & No (20) & Yes (21) & No (22) & Yes (19) \\
\hline Age (years) & $58[50-75]$ & 59 [43-69] & $57[50-75]$ & 60 [43-69] & $58[50-75]$ & 59 [43-69] & $\begin{array}{l}59.5[48- \\
75]\end{array}$ & 58 [43-68] & 59 [43-75] & 58 [46-69] \\
\hline Education (years) & $13[5-16]$ & 12 [9-18] & $14[5-16]$ & 12 [9-18] & $13[5-16]$ & 12 [9-18] & $14[5-18]$ & $12[9-16]$ & $12[5-18]$ & $12[9-16]$ \\
\hline $\begin{array}{l}\text { Contact with offspring } \\
\qquad \%(n)\end{array}$ & $31.2(5)$ & $56.0(14)$ & $30.8(4)$ & $53.6(15)$ & $27.8(5)$ & $60.9(14)^{n}$ & $35.0(7)$ & $57.1(12)$ & $45.5(10)$ & $47.4(9)$ \\
\hline KAST score & $14.5[8-18]$ & 16 [8-18] & 16 [8-18] & $15.5[8-18]$ & 14.5 [8-18] & $16[8-18]$ & $15.5[8-18]$ & $16[11-18]$ & 15 [8-18] & $16[8-18]$ \\
\hline PRS score & $\begin{array}{l}58.5[36- \\
12]\end{array}$ & $52.5[36-88]$ & 59 [36-121] & 54 [36-92] & $\begin{array}{l}58.5[36- \\
121]\end{array}$ & $52.5[37-88]$ & $67[46-121]$ & $\begin{array}{l}47[36- \\
88]^{\mathrm{nn}}\end{array}$ & $\begin{array}{l}58.5[36- \\
121]\end{array}$ & 55 [36-88] \\
\hline \multicolumn{11}{|l|}{ Cognitive factors : } \\
\hline Updating score & $\begin{array}{l}20.4[12- \\
25.8]\end{array}$ & $\begin{array}{l}23.6[12.5- \\
33.5]^{\mathrm{n}}\end{array}$ & $\begin{array}{l}21.4[15- \\
25.8]\end{array}$ & $\begin{array}{l}23.3[12- \\
33.5]\end{array}$ & $\begin{array}{l}20.4[12- \\
33.5]\end{array}$ & $\begin{array}{l}23.6[12.5- \\
31.3]^{n}\end{array}$ & $\begin{array}{l}22[14.3- \\
29]\end{array}$ & $\begin{array}{l}23[12- \\
33.5]\end{array}$ & 21 [12-31.3] & $\begin{array}{l}25.3[14.5- \\
33.5]^{\mathrm{n}}\end{array}$ \\
\hline $\begin{array}{l}\text { WCST-nb categ. } \\
\text { completed }\end{array}$ & $6[3-6]$ & $6[4-6]$ & $6[3-6]$ & $6[3-6]$ & $6[3-6]$ & $6[4-6]$ & $6[3-6]$ & $6[4-6]$ & $6[3-6]$ & $6[4-6]$ \\
\hline WCST-nb persev. errors & $10[5-36]$ & 7 [3-37] & $10[5-36]$ & $8[3-37]$ & $10[5-36]$ & 7 [3-37] & 10 [4-36] & $8[3-37]$ & $12[5-36]$ & $6.5[3-37]^{n}$ \\
\hline WCST- $\%$ persev.errors & $\begin{array}{l}11.9[6.8- \\
28.6]\end{array}$ & 8.6 [4.3-28.9] & $\begin{array}{l}11.2[6.5- \\
28.6]\end{array}$ & $\begin{array}{l}9.8[4.3- \\
28.9]\end{array}$ & $\begin{array}{l}11.9[6.7- \\
28.6]\end{array}$ & $8.6[4.3-28.9]$ & $\begin{array}{l}11.2[5.9- \\
28.6]\end{array}$ & $\begin{array}{l}9.4[4.3- \\
28.9]\end{array}$ & $\begin{array}{l}13.3[6.8- \\
28.6]\end{array}$ & $\begin{array}{l}8.2[4.3- \\
28.9]^{\mathrm{n}}\end{array}$ \\
\hline BADS score & 93 [63-119] & 98 [58-123] & $\begin{array}{l}95.5 \text { [63- } \\
119]\end{array}$ & 98 [58-123] & 93 [63-119] & $98[58-123]^{n}$ & 98 [63-119] & $\begin{array}{l}98 \text { [58- } \\
123]\end{array}$ & 98 [58-119] & 98 [73-123] \\
\hline
\end{tabular}

Note: $\mathrm{p}$-value from $\mathrm{x}^{2}$ Test or Fischer Exact Test for categorical variables and Wilcoxon Rank Sum Test for continuous variables. KAST: Knowledge about Schizophrenia Test;

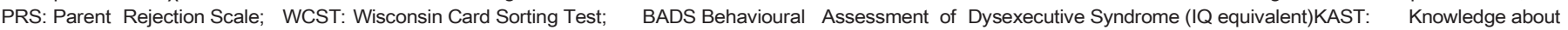
Schizophrenia Test; PRS: Parent Rejection Scale; WCST: Wisconsin Card Sorting Test; BADS Behavioural Assessment of Dysexecutive Syndrome (IQ equivalent).

${ }^{n}$ po0.05.

nn po0.01.

patients. It is also possible that illness and poor insight of the patient may influence the cognitive performances of their ageing parents. The mechanisms underlying this finding need to be further explored.

Our study has several limitations. Firstly, patients and parents had to have sufficiently good insight to consent to taking part in the study, which may explain the high level of parental insight especially for the first three dimensions of the SUMD; thus we may have lacked sufficient variability to show correlations with patients' insight. Using another scale to measure insight might have helped avoid this, yet the SUMD is to our knowledge the most appropriate instrument for assessing clinical insight in schizophrenia and it is essential to use the same tool in both groups. Despite first-degree relatives of schizophrenia patients having an increased risk of psychosis (Erlenmeyer-Kimling et al., 1997), we were unable to study the impact of family history of psychosis or parental psychopathology on insight, due to the absence of psychotic disorders in the parent group. This is no doubt due to participation bias.

Regarding agreement between patients and their parents as to insight, it is difficult to compare our results to other studies as no one study has used the same instrument in the same type of patient and parent/caregiver dyads. For instance, Smith et al. (1997) used the SUMD in a sample of 22 patients who generally agreed with their significant others for all SUMD dimensions except for symptom attribution where parents scored significantly better. This could be due to the fact that it was the patient who designated the "significant other", and most often they would have chosen someone whom they trusted and did not contradict them concerning their illness. Brent et al. (2011) used the SUMD in a group of 14 first episode psychotic patients and caregivers, found that caregivers had a significantly higher level of awareness than the patient of his/her mental illness and of its social consequences. Our study shows the same result for all patient- parent dyads, but not when stratifying by frequency of daily contacts, no doubt due to a lack of statistical power. On the other hand, in keeping with Brent et al., we found a significant correlation between patient and parents for the awareness of the need for treatment in dyads with frequent contact. Tranulis et al. (2008) using the "Extracted Insight Score", showed an overall correlation between caregiver and patient insight, partly attributable to a greater variability in insight scores linked to the choice of the scoring method; however they do not provide dimension-specific results. Gigante and Castel (2004) using the SAI found modest significant correlations between patients and caregivers for two of the three dimensions explored (adherence to treatment, recognition of mental illness but not ability to relabel psychiatric phenomena as abnormal).

Nonetheless, none of the studies explored associations between family factors and patient insight as they all focused on caregivers who were in frequent contact with the patient. The novelty of our study is to have included biological parents only. Our findings suggest the association between patient and parent insight may not only depend on the biological relationship between the two, but on the frequency of daily contact and thus the immediate environment. When patient and parent dyads were stratified depending on daily contact, we found a moderate correlation between patient and parent insight for the awareness of treatment effect for dyads who were in daily contact, in accordance with the literature (Gigante and Castel, 2004; Brent et al., 2011). Parental insight will indeed be of limited relevance to patients' insight in the event of very infrequent contacts. Our findings also support the role of environmental factors on patient insight. Thus encouraging regular contact between patients and their family should be another objective for clinical teams. The concept of 'pseudo-insight' (Mcgorry and McConville, 1999) where a patient's awareness of disease seems to improve over time due to his increasing understanding of what is expected of him by clinicians and entourage (i.e. the patient says that he/she suffers 
from a disease because he/she knows that it is the awaited response), is however criticised by recent longitudinal studies highlighting the lack of improvement of insight over time especially in chronic schizophrenia patients compared to first episode ones (Koren et al., 2013). Certainly such environmental factors have a role to play but they cannot solely be held responsible for the complexity of patient insight.

\section{Conclusion}

Despite not showing an association between patient and parental insight, our study highlights the importance of frequent contact between the parent and the patient and the influence of parental critical attitudes on patients' insight; and thus the need to develop, innovate and generalise family interventions in order to improve attitude and thus indirectly improve patient insight. Furthermore, our study is the first to focus on biological parents and to demonstrate an association between parents cognitive functioning and their offspring's awareness of some aspects of their illness thus supporting the multidimensional model of insight in schizophrenia. Studies recruiting patients as well their biological parents and caregivers are needed to further explore over time the link between parent and patient insight and parental factors such as cognition.

Conflicts of interest

The authors have no conflict of interest to declare.

\section{Role of funding source}

This study was funded by the Montpellier University Hospital (Grant No. 8742), who had no further role in the design of study, subject recruitment or the data analysis.

\section{Acknowledgements}

We wish to thank all patients and parents who participated in this study.

\section{References}

Aleman, A., Agrawal, N., Morgan, K.D., David, A.S., 2006. Insight in psychosis and neuropsychological function: meta-analysis. British Journal of Psychiatry 189 , 204-221.

Amador, X.F., Flaum, M., Andreasen, N.C., Strauss, D.H., Yale, S.A., Clark, S.C., 1994 Awareness of illness in schizophrenia and schizoaffective and mood disorders. Archives of General Psychiatry 51, 826-836.

Amador, X.F., Strauss, D.H., Yale, S.A., Flaum, M.M., Endicott, J., Gorman, J.M., 1993. Assessment of insight in psychosis. American Journal of Psychiatry 150, 873-879.

American Psychiatric Association, 1994. Diagnostic and Statistical Manual of Mental Disorders. American Psychiatric Association, Washington, DC.

Angermeyer, M.C., Holzinger, A., Carta, M.G., Schomerus, G., 2011. Biogenetic explanations and public acceptance of mental illness: systematic review of population studies. British Journal of Psychiatry 199, 367-372.

Boyer, L., Aghababian, V., Richieri, R., Loundou, A., Padovani, R.R., Simeoni, M.C. Auquier, P., Lançon, C., 2012. Insight into illness, neurocognition and quality of life in schizophrenia. Progress in Neuro-Psychopharmacology and Biological Psychiatry 36, 271-276.

Brent, B.K., Giuliano, A.J., Zimmet, S.V., Keshavan, M.S., Seidman, L.J., 2011. Insight into illness in patients and caregivers during early psychosis: a pilot study. Schizophrenia Research 127, 100-106.

Brent, B.K., Seidman, L.J., Coombs, G., Keshavan, M.S., Moran, J.M., Holt, D.J., 2014. Neural responses during social reflection in relatives of schizophrenia patients: relationship to subclinical delusions. Schizophrenia Research 157 292-298.
Compton, M.T., Quintero, L., Esterberg, M.L., 2007. Assessing knowledge of schizophrenia: development and psychometric properties of a brief, multiple-choice knowledge test for use across various samples. Psychiatry Research 151, 87-95.

Danki, D., Dilbaz, N., Okay, I.T., Telci, S., 2007. Insight in schizophrenia : relationship to family history, and positive and negative symptoms. Turkish Journal of Psychiatry $18, \quad 1-8$

Erlenmeyer-Kimling, L., Adamo, U.H., Rock, D., Roberts, S.A., Bassett, A.S., SquiresWheeler, E., Cornblatt, B.A., Endicott, J., Pape, S., Gottesman, I.I., 1997. The New York High-Risk Project. Prevalence and comorbidity of axis I disorders in offspring of schizophrenic parents at 25-year follow-up. Archives of General Psychiatry 54, 1096-1102.

First, M.B., Spitzer, R.L., Gibbon, M., Williams, J.B.W., 2000. Structured Clinical Interview for DSM-IV (SCID) Axis I Disorders. American Psychiatric Press, Washington, DC

Gigante, A.D., Castel, S., 2004. Insight into schizophrenia: a comparative study between patients and family members. São Paulo Medical Journal 122, 246-251.

Goodvin, R., Meyer, S., Thompson, R.A., Hayes, R., 2008. Self-understanding in early childhood: associations with child attachment security and maternal negative affect. Attachment \& Human Development 10 (4), 433-450.

Johnson, S., Orrell, M., 1995. Insight and psychosis: a social perspective. Psychological Medicine 25, 515-520.

Kenny, D., Kashy, D., Cook, W., 2006. In Dyadic Data Analysis. Guilford Publications, New York, USA.

Koren, D., Viksman, P., Giuliano, A.J., Seidman, L.J., 2013. The nature and evolution of insight in schizophrenia : a multi-informant longitudinal study of first-episode versus chronic patients. Schizophrenia Research 151, 245-251.

Kreisman, D.E., Blumenthal, R., Borenstein, M., Woerner, M.G., Kane, J., Rifkin, A., Reardon, G., 1988. Family attitudes and patient social adjustment in a longitudinal study of outpatient schizophrenics receiving low-dose neuroleptics: the family's view. Psychiatry 51, 3-13.

Kreisman, D.E., Simmens, S.J., Joy, V.D., 1979. Rejecting the patient: preliminary validation of a self-report scale. Schizophrenia Bulletin 5, 220-222.

Lançon, C., Reine, G., LLorca, P.M., Auquier, P., 1999. Validity and reliability of the French-language version of the Positive and Negative Syndrome Scale (PANSS) Acta Psychiatrica Scandinavica 100, 237-243.

Liemburg, E.J., van der Meer, L., Swart, M., Curcic-Blake, B., Bruggeman, R., Knegtering, H., Aleman, A., 2012. Reduced connectivity in the self-processing network of schizophrenia patients with poor insight. PloS One 7, e42707.

Lincoln, T.M., Lüllmann, E., Rief, W., 2007. Correlates and long-term consequences of poor insight in patients with schizophrenia. A systematic review. Schizophrenia Bulletin 33, 1324-1342.

Lysaker, P.H., Bryson, G.J., Lancaster, R.S., Evans, J.D., Bell, M.D., 2003a. Insight in schizophrenia: associations with executive function and coping style. Schizophrenia Research 59, 41-47.

Lysaker, P.H., Lancaster, R.S., Davis, L.W., 2003b. Patterns of neurocognitive deficits and unawareness of illness in schizophrenia. The Journal of Nervous and Mental Disease 191, 38-44.

Mcgorry, P.D., McConville, S.B., 1999. Insight in psychosis: an elusive target. Comprehensive Psychiatry 40, 131-142.

McWilliams, S., Egan, P., Jackson, D., Renwick, L., Foley, S., Behan, C., Fitzgerald, E., Fetherston, A., Turner, N., Kinsella, A., O'Callaghan, E., 2010. Caregiver psychoeducation for first-episode psychosis. European Psychiatry 25, 33-38.

Morris, N., Jones, D.M., 1990. Habituation to irrelevant speech: effects on a visual short-term memory task. Percept Psychophys 47, 291-297.

Nelson, H.E., 1976. A modified card sorting test sensitive to frontal lobe defects. Cortex 12, 313-324.

Pijnenborg, G.H.M., van Donkersgoed, R.J.M., David, A.S., Aleman, A., 2013. Changes in insight during treatment for psychotic disorders: a meta-analysis. Schizophrenia Research 144, 109-117.

Pruß, L., Wiedl, K.H., Waldorf, M., 2012. Stigma as a predictor of insight in schizophrenia. Psychiatry Research 198, 187-193.

Raffard, S., Bayard, S., Gely-Nargeot, M.-C., Capdevielle, D., Maggi, M., Barbotte, E., Morris, D., Boulenger, J.-P., 2009. Insight and executive functioning in schizophrenia : a multidimensional approach. Psychiatry Research 167, 239-250.

Raffard, S., Bortolon, C., Macgregor, A., Norton, J., Boulenger, J.-P., Haj, El, M., Capdevielle, D., 2014. Cognitive insight in schizophrenia patients and their biological parents: a pilot study. Schizophrenia Research 159, 471-477.

Raffard, S., Trouillet, R., Capdevielle, D., Gely-Nargeot, M.-C., Bayard, S., Larøi, F., Boulenger, J.-P., 2010. La SUMD (Scale to Assess Unawareness of Mental Disorder): validation et adaptation française dans une population de patients souffrant de schizophre 'nie. The Canadian Journal of Psychiatry 55, 523-531.

Raij, T.T., Riekki, T.J.J., Hari, R., 2012. Association of poor insight in schizophrenia with structure and function of cortical midline structures and frontopolar cortex. Schizophrenia Research 139, 27- 32.

Schwartz, R.C., Cohen, B.N., Grubaugh, A., 1997. Does insight affect long-term inpatient treatment outcome in chronic schizophrenia? Comprehensive Psychiatry $38,283-288$.

Sellwood, W., Tarrier, N., Quinn, J., Barrowclough, C., 2003. The family and compliance in schizophrenia: the influence of clinical variables, relatives knowledge and expressed emotion. Psychological Medicine 33, 91-96.

Shad, M.U., Tamminga, C.A., Munro Cullum, C., Haas, G.L., Keshavan, M.S., 2006. Insight and frontal cortical function in schizophrenia: a review. Schizophrenia Research 86, 54-70.

Smith, C.M., Barzman, D., Pristach, C.A., 1997. Effect of patient and family insight on compliance of schizophrenic patients. Journal of Clinical Pharmacology 37, 147-154. 
Snitz, B.E., Macdonald, A.W., Carter, C.S., 2006. Cognitive deficits in unaffected firstdegree relatives of schizophrenia patients: a meta-analytic review of putative endophenotypes. Schizophrenia Bulletin 32, 179-194.

Tranulis, C., Corin, E., Kirmayer, L.J., 2008. Insight and psychosis: comparing the perspectives of patient, entourage and clinician. The International Journal of Social Psychiatry 54, 225-241.

van der Meer, L., de Vos, A.E., Stiekema, A.P.M., Pijnenborg, G.H.M., van Tol, M.-J., Nolen, W.A., David, A.S., Aleman, A., 2013. Insight in schizophrenia: involvement of self-reflection networks? Schizophrenia Bulletin 39, 1288-1295.

Vaughn, C.E., Leff, J.P., 1981. Patterns of emotional response in relatives of schizophrenic patients. Schizophrenia Bulletin 7 (1), 43-44

White, R., Bebbington, P., Pearson, J., Johnson, S., Ellis, D., 2000. The social context of insight in schizophrenia. Social Psychiatry and Psychiatric Epidemiology 35, 500-507.
Whitfield-Gabrieli, S., Thermenos, H.W., Milanovic, S., Tsuang, M.T., Faraone, S.V., McCarley, R.W., Shenton, M.E., Green, A.I., Nieto-Castanon, A., LaViolette, P. Wojcik, J., Gabrieli, J.D., Seidman, L.J., 2009. Hyperactivity and hyperconnectivity of the default network in schizophrenia and in first-degree relatives of persons with schizophrenia. Proceedings of the National Academy of Science USA 106 (4), 1279-1284.

Wiffen, B.D.R., O'Connor, J.A., Gayer-Anderson, C., Marques, T.R., McQueen, G., Happé, F., Murray, R., David, A.S., 2013. "I am sane but he is mad" Insight and illness attributions to self and others in psychosis. Psychiatry Research 207, 173-178.

Wilson, B.A., Alderman, N., Burguess, P.W., Emslie, J.J., 1996. Manual of the Behavioural Assessment of the Dysexecutive Syndrome. Thames Valley Test Company, Bury St Edmunds, UK. 